\title{
A Note on Presuppositions, Conventions, and Translations
}

I

$\mathbf{N}$ recent years the literature on Frege has become increasingly techni-

cal, some of it readable only by specialists immersed in disputes concerning the extensive secondary sources, the technical details of his notation and constructions, or the appropriate translation of his writings. Although I am not writing an introduction to Frege's writings, this book is also not addressed solely to specialists. I shall therefore take the opportunity here not only to introduce some of the abbreviations and conventions I use, but also to indicate the background I am presupposing.

Long before I had any acquaintance with Frege's writings, outside of reading "On Sense and Meaning" (or "On Sense and Reference," as it was known then) in an introductory philosophy of language course; I had been taught that Frege introduced the first version of the logical notation used today, that he attempted to show that arithmetic was analytic by proving the truths of arithmetic from the truths of logic, and that this proof failed because one of his logical laws, Basic Law V, was inconsistent with the others. More generally I thought of Frege as having introduced contemporary philosophical ways of thinking about language and mathematics as well as logic. I have tried to write a book that presupposes no information about Frege's writings other than this. As I mentioned above, however, this is not an introduction to Frege's works. I have attempted neither to catalog and explain his major views nor to introduce and evaluate generally accepted interpretations. 
In the interest of making this book accessible to the nonspecialist, I have confined most of the discussion of secondary sources, as well as the more intricate textual interpretations and most uses of logical notation, to footnotes and appendixes. Also, since virtually all Frege's writings are available in translation, my citations are generally to the translations only, and I have for the most part quoted only the English translations. In a few cases I have found it necessary to refer to untranslated passages from Basic Laws and hence the only citation is to a German text. There are, however, a few exceptions that must be explained here.

The issue of how Frege's term Bedeutung and its cognates should be translated into English has become a matter of controversy. Although 'meaning' is used in most translations currently in print, until recently the more popular choices were 'reference' and 'denotation'. Since part of my aim is to explain how Frege's use of this term is to be understood and since each of the translations mentioned here can appear to presuppose a particular explanation, I have often chosen to leave Bedeutung untranslated and to treat it as an English term. I apologize for the infelicity of expression which results. In some of the passages I have quoted there seemed to me to be a potential for confusion, and I have indicated, in these cases, when an English word is meant as a translation of Bedeutung or one of its cognates. Here and in other quoted translations when I thought it would be helpful to include a German phrase or word, I have cited both the English translation and a German publication.

Another of Frege's terms which has been left untranslated and treated as an English term is 'Begriffsschrift'. It has no natural English translation, and the convention of using the German has already been established in Montgomery Furth's translation of Basic Laws. Following Furth, I have used the term unitalicized to talk about Frege's logical notation and, in some cases, about his logical system. When it is italicized I am employing it as an abbreviation of the title of the work in which Frege's logic was first introduced, Begriffsschrift, eine der arithmetischen nachgebildete Formelsprache des reinen Denkens.

Frege's logical notation presents another problem. Although it is, in a very important sense, the ancestor of the logical notations employed today, the actual symbols Frege used are quite foreign to contemporary philosophers who are not Frege scholars. I have not tried to introduce and explain his symbols, since I have very little need for them here. My concern is not with the formal details of Frege's accomplishments but 
A Note on Presuppositions, Conventions, and Translations / xxi

with the underlying philosophical view. In a few discussions, when it is necessary to talk about Frege's logical regimentation, I have made use of contemporary logical symbols. Only in a very few technical analyses that appear in footnotes and in one appendix have I talked about and used Frege's actual symbols. These discussions are addressed to specialists and can be skipped by most readers. 
